\title{
A Combined Self-Assembled Drug Delivery for Effective Anti-Breast Cancer Therapy
}

This article was published in the following Dove Press journal:

International Journal of Nanomedicine

\author{
Hairong Wang \\ Yawen Zhang \\ Xiangle Zeng \\ Wenjun Pei \\ Ranran Fan \\ Yushuai Wang \\ Xiu Wang \\ Jianchun Li
}

School of Pharmacy, Bengbu Medical College, Bengbu, 233030, People's

Republic of China
Correspondence: Jianchun Li

School of Pharmacy, Bengbu Medical

College, Bengbu, 233030, People's

Republic of China

Tel +86552-3175066

Email Lijc66577@sohu.com

\begin{abstract}
Aim: The metastasis of breast cancer is an important cause of tumor recurrence. This study highlights that tyrosine kinase inhibitors dasatinib (DAS) and rosiglitazone (ROZ) inhibit tumor growth and reduce the occurrence of tumor cell metastasis. Due to the poor water solubility, short half-time in the body of DAS and ROZ, which increases the difficulty of tumor treatment, as well as the demand for nano-drug delivery systems for organ-specific therapies.
\end{abstract}

Methods: Hyaluronic acid (HA) and DAS are bonded by a $\mathrm{pH}$-sensitive ester bond to form an HA-DAS polymer. Then, ROZ was added as the core, D-A-tocopherol polydiethylene glycol isosuccinate (TPGS) and HA-DAS were used as carriers to form HA-DAS and TPGS mixed micelle system loaded with ROZ (THDR-NPs). The size and structure of THDR-NPs were characterized, the drug release, stability and biosafety of THDR-NPs were studied. In vitro, the cytotoxicity, targeting effect and tumor metastasis inhibition of THDR-NPs were evaluated in human breast cancer cell lines. In addition, the selective potency of designed THDR-NPs in depleting was further verified in vivo in the tumor-bearing nude mice model. Results: The designed THDR-NPs have a particle size of less than $100 \mathrm{~nm}$, good stability, biological safety and sustained release, and showed strong therapeutic effects on breast cancer models in vitro and in vivo. Moreover, it has been proved that THDR-NPs have the ability to inhibit tumor metastasis.

Conclusion: DAS and ROZ were designed into micelles, the efficacy of THDR-NPs was higher than that of free drugs. These results indicate that nanoparticles have a good application prospect in the treatment of tumor metastasis.

Keywords: HA targeting, inhibiting metastasis, polymer, micelle

\section{Introduction}

Breast cancer, one of the highest incidence of tumors in women, which seriously threatens women's health, its morbidity and mortality are on the rise and tend to be younger. ${ }^{1,2}$ Therefore, it is very necessary to find an effective treatment for breast cancer. Metastasis is still an unsolved difficulty in current breast cancer treatment, which reduces the effectiveness of breast cancer therapy. ${ }^{3}$ During the metastasis of breast cancer cells, epithelial-mesenchymal transition (EMT) refers to the transformation of tumor epithelial cells into cells with a mesenchymal phenotype through a specific process. ${ }^{4}$ The plasticity and metastasis of cancer cells are significantly enhanced, which helps cancer cells avoid chemotherapy and targeted therapy, and is the main reason for the invasion of primary tumor cells.

Nowadays, many studies are devoted to the transformation of tumor cells from mesenchymal phenotype to epithelial phenotype (MET), thereby reducing the 
invasiveness of tumor cells and enhancing the therapeutic effect. At the same time, there is an unresolved question: whether the tumor cells that induce the MET process can be through the secondary EMT process, differentiation and transfer again. ${ }^{5}$ Recent studies have shown that using a cross-differentiation method to target and inhibit the plasticity of tumor cells, such as combining tyrosine kinase inhibitors with rosiglitazone (ROZ) to force adipogenesis, can effectively inhibit the proliferation and invasion of cancer cells, providing a new idea for cancer treatment. 6

Dasatinib (DAS) is a small-molecular multi-target kinase inhibitor that slows the growth of cancer cells by altering hormone receptor signaling and blocking signaling pathways involved in tumor metastasis. ${ }^{7}$ Studies have found that DAS has shown a good therapeutic effect on a variety of solid tumors, including gastrointestinal stromal tumors, melanoma, head and neck cancer, prostate cancer, lung and ovarian cancer, and breast cancer. ${ }^{8-10}$ In the treatment of breast cancer, DAS has been used in clinical trials for triple-negative, human epidermal growth factor receptor-2 (HER-2) positive and hormone receptor positive diseases, and is supported by preclinical data. ${ }^{8,11}$ ROZ, a peroxisome proliferator-activated receptor- $\gamma$ (PPAR- $\gamma$ ) agonist, is mainly used clinically for the treatment of type 2 diabetes. ${ }^{12}$ Studies have found that it can induce adipogenesis and then promote the proliferation of fat cells, inhibit the possibility of cancer cell metastasis, and treat tumors. ${ }^{13}$

In the combination of DAS and ROZ, DAS inhibits the mitogen-activated protein kinase pathway, interferes with the proliferation and differentiation of tumor cells, keeps tumor cells in the late stage of mitosis. ROZ can induce the acceleration of adipogenesis of tumor cells at anaphase of mitosis with strong plasticity, and ultimately reduces the invasion ability of tumor cells, which is conducive to subsequent tumor therapy. However, there are still many problems in practical applications. $^{14,15}$ For example, DAS has a short halflife, which is easily affected by $\mathrm{pH}$ adjusters and is prone to drug interactions with cytochrome $\mathrm{P} 450$ (CYP) 3A4 inducers or inhibitors. Both drugs have poor water solubility, the bioavailability of the combination is poor, and it is planned to use nanoparticle to solve the existing problems.

With the development of nanomaterial technology, various new dosage forms have brought new opportunities for disease treatment. Micelles have high drug loading, encapsulation efficiency and long circulation time in the body, and have broad application prospects. Moreover, it can be passively enriched in tumor tissue compared with normal tissues and has a tumor tissue retention effect, or the polymer micelles can be modified with protein ligands and $\mathrm{pH}$-sensitive ester bonds for the purpose of protein targeting and $\mathrm{pH}$-sensitive targeting to achieve targeted drug delivery and reduce the toxic and side effects of drugs on normal tissues. ${ }^{16-19}$

The expression of CD44 protein is abnormally increased in tumor cells, so it is often used as a tumor treatment target to prepare active targeting agents. HA as the most important ligand of CD44 protein, is also used as a target material to prepare active targeting agents. $^{20}$ The complex of CD44 protein and its ligand HA is hydrolyzed by acid hydrolase, afterwards, HA is separated from the complex to release the drug. ${ }^{21,22}$ The HA-based nano-drug delivery system can make the drug more concentrated and target the tumor site, thereby improving the bioavailability of the drug. D-a-tocopheryl polyethylene glycol isosuccinate (TPGS), its structure contains both lipophilic tocopherol groups and hydrophilic polyethylene glycol long-chain groups, which has obvious advantages used as drug carriers to increase the solubility of poorly soluble drugs, improve the stability of the formulation and reduce the particle size of the formulation. In recent years, it has been widely used in nanoformulations. ${ }^{23-25}$

Due to the insoluble properties of DAS and ROZ and the aggressive characteristics of tumor cells. Hyaluronic acid (HA) and DAS are bonded by a $\mathrm{pH}-$ sensitive ester bond to form an HA-DAS polymer. Then, ROZ was added as the core, D-A-tocopherol polydiethylene glycol isosuccinate (TPGS) and HADAS were used as carriers to form HA-DAS and TPGS mixed micelle system loaded with ROZ (THDRNPs). Compound micelles can well increase the solubility as well as drug stability of DAS and ROZ, the half-life of micellar was prolonged, and the retention effect was enhanced. Among them, HA has the biological function of targeting tumor cells, TPGS can enhance the stability of micelles, and $\mathrm{pH}$-sensitive ester bonds can break in response to the acidic microenvironment of tumor site and release drugs. ${ }^{26,27}$ Thereby, it is more effective on inhibiting tumor growth and metastasis, providing theoretical basis and new ideas for tumor treatment (Scheme 1). 


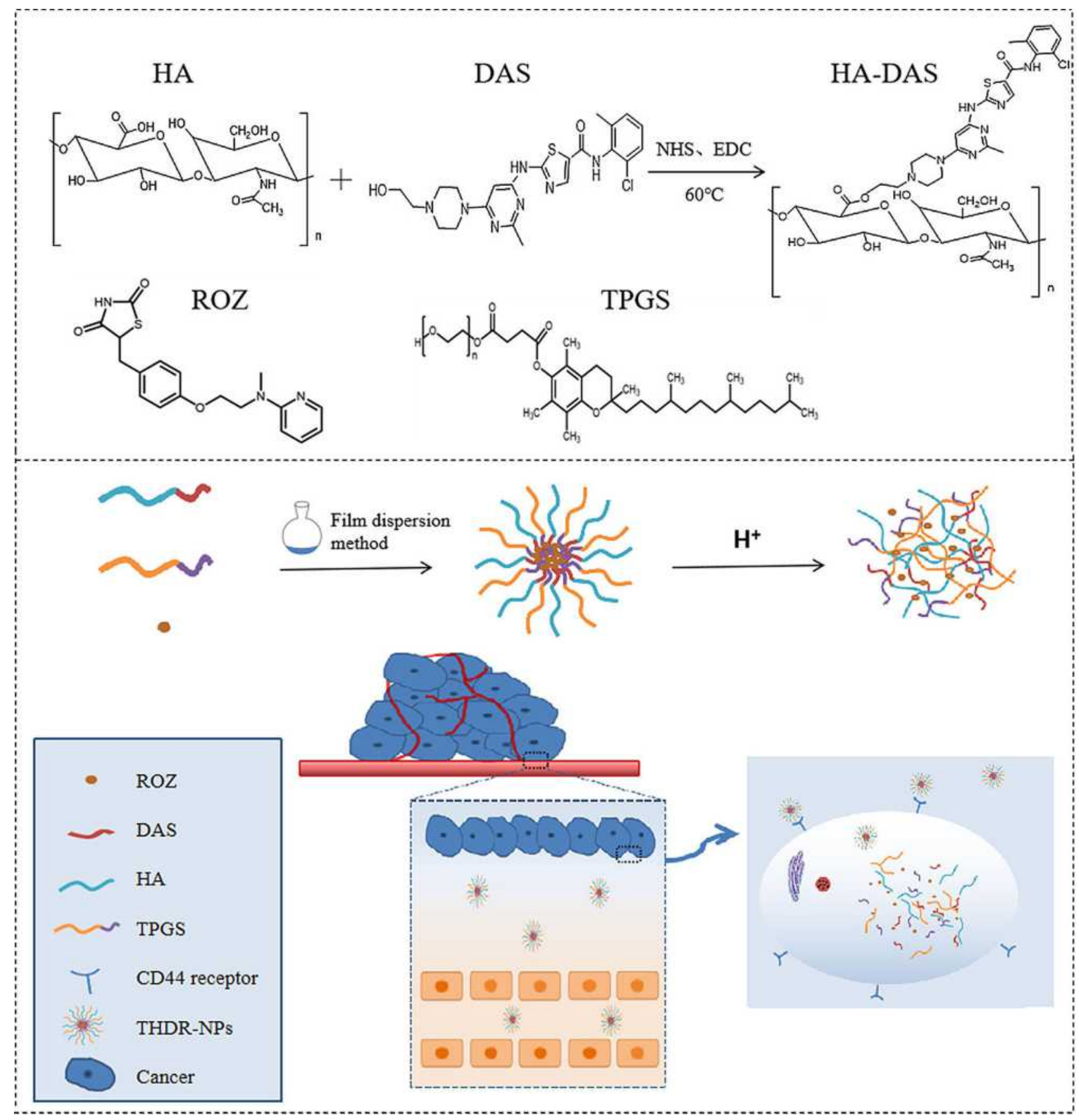

Scheme I Schematic diagram of the role of THDR-NPs carrier for co-delivery of DAS and ROZ.

\section{Materials and Methods Materials}

HA was acquired from Huaxi Biological Technology Co. Ltd. (Jinan, China). DAS, ROZ, and TPGS were purchased from Macklin Co. Ltd. (Shanghai, China). EDC and DMAP were purchased from Aladdin Co. Ltd. (Shanghai, China). Both methanol and acetonitrile were chromatographic grade. And Luna C-8 HPLC columns were from Phenomenex (Torrance, CA, USA).

\section{Animals and Cell Lines}

Human tumor cell lines MCF-7 and MDA-MB-231 were purchased from Procell Life Science\&Technology Co., Ltd. (Wuhan, China). MCF-7 cells were maintained at 5\% 
$\mathrm{CO}_{2}, 37^{\circ} \mathrm{C}$, and $1 \%$ penicillin and streptomycin and $10 \%$ fetal bovine serum were (FBS) added to DMEM medium. MDA-MB-231 cells were kept at 5\% carbon dioxide, $37^{\circ} \mathrm{C}$ and in RPMI 1640 medium with 1\% penicillin and streptomycin and $10 \%$ fetal bovine serum (FBS). BALB/c nude mice (female, 4-5 weeks) and SD rats were obtained from Cavins Laboratory Animal Co., Ltd. (Changzhou, China). All animal procedures comply with animal ethics requirements. The animal experimental procedure was approved by the Animal Care Committee of Bengbu Medical College (License No.: 2018033) on 19 January 2018 and conformed to the Animal Ethical Standards and Use Committee at Bengbu Medical College.

\section{Synthesis and Characterization of HA-DAS Polymer}

Firstly, HA (533.33 mg, $0.2 \mathrm{mmol})$, DMAP (13.03 mg, $0.32 \mathrm{mmol})$ and $\mathrm{EDC} \cdot \mathrm{HCl}(31.95 \mathrm{mg}, 0.5 \mathrm{mmol})$ were dissolved in $10 \mathrm{~mL}$ DMSO $/ \mathrm{H}_{2} \mathrm{O}$ mixed medium $(\mathrm{v} / \mathrm{v}$, $1: 1$ ), the mixed reaction solution was stirred at $60^{\circ} \mathrm{C}$ for $4 \mathrm{~h}$ to activate the carboxyl group. Subsequently, DAS (32.53 $\mathrm{mg}, 0.2 \mathrm{mmol}$ ) was added to the mixed solution, and the reaction was kept stirring at $60^{\circ} \mathrm{C}$ for $24 \mathrm{~h}$. Then, the product was added to dialysis bag (MWCO $3.5 \mathrm{k} \mathrm{Da})$ followed by dialyzed with $\mathrm{PBS}(\mathrm{pH} 7.4,0.01 \mathrm{M})$ as dialysate for 3 days, the suspension was filtered through a filter membrane $(0.45 \mu \mathrm{m})$, freeze-dried to obtain the product HA-DAS polymer.

\section{Preparation of $\mathrm{pH}$-Sensitive ROZ-Loaded Mixed Micelles}

pH-sensitive ROZ-loaded mixed micelles were prepared by thin-film dispersion method. ${ }^{28}$ In short, $17 \mathrm{mg}$ of HADAS, $3 \mathrm{mg}$ of TPGS, $2 \mathrm{mg}$ of ROZ were mixed uniformly with $10 \mathrm{~mL} \mathrm{H}_{2} \mathrm{O} /$ methanol mixed solution (v/v, 1:1) by ultrasonic. Hereafter the solvent was removed with a rotary evaporator to obtain a drug film which was dissolved with PBS (pH 7.4, 0.01 M). Finally, filter through the membrane to obtain micellar solution (THDR-NPs).

\section{Characterization}

Differential scanning calorimeter was used to evaluate whether the HA-DAS polymer exists in the form of physical mixing or chemical synthesis, and then the molecular structure of the polymer was analyzed by ${ }^{1} \mathrm{H}-\mathrm{NMR}$ spectroscopy at $500 \mathrm{MHz}$ by using $\mathrm{D}_{2} \mathrm{O}$ as dialysate. The particle size, zeta potential and PDI of THDR-NPs were measured by Malvern Zetasizer Nano ZSE, characterization of THDR-NPs particle morphology was performed using transmission electron microscopy (TEM). The concentration was measured by a high-performance liquid chromatograph (HPLC) and then the drug loading (DL) and encapsulation efficiency (EE) were calculated according to the following Equations 1 and 2.

$$
\begin{aligned}
& \mathrm{DL} \%=\frac{\text { Weight of drug in mixed micelles }}{\text { Weight of mixed micelles }} \times 100 \% \\
& \mathrm{EE} \%=\frac{\text { Weight of drug in mixed micelles }}{\text { Weight of drug added }} \times 100 \%
\end{aligned}
$$

\section{Critical Micelle Concentration (CMC) of THDR-NPs}

The CMC value of THDR-NPs was determined by fluorescence measurement using pyrene as a fluorescent probe. In short, pyrene was dissolved in acetone and the solvent was evaporated. Then, HA-DAS and TPGS solution were added to pyrene, and micelle was formed by thin-film hydration. The THD-NPs solution concentration ranged from $1.0 \times 10^{-5}$ to $1.0 \times 10^{-1} \mathrm{mg} / \mathrm{mL}$. The final concentration of pyrene was maintained at $6.0 \times$ $10^{-6} \mathrm{M}$. The fluorescence intensity was measured by a fluorescence spectrophotometer, the Ex was $550 \mathrm{~nm}$, and the Em was $570 \mathrm{~nm}$. When extrapolating the intensity of the low concentration and high concentration regions, the $\mathrm{CMC}$ was determined as the intersection point.

\section{Hemolysis Test}

A $30 \mu \mathrm{L}$ of blood was collected from the ocular venous plexus of normal SD rats to heparin-coated centrifuge tubes, followed by centrifugation $(2000 \mathrm{rpm})$ at $4^{\circ} \mathrm{C}$ for $10 \mathrm{~min}$. Then, the lower red blood cells (RBC) were collected and diluted with PBS ( $\mathrm{pH} 7.4,0.01 \mathrm{M})$. A 100 $\mu \mathrm{L}$ of the diluted RBCs suspension was incubated with $100 \mu \mathrm{L}$ PBS (pH 7.4, $0.01 \mathrm{M}$ ) containing NPs with different drug concentrations $(\mu \mathrm{g} / \mathrm{mL})$. The mixtures were left at $37^{\circ} \mathrm{C}$ for $2 \mathrm{~h}$ under gentle shaking. Immediately after centrifugation ( $5000 \mathrm{rpm}, 5 \mathrm{~min}$ ), the absorbance of the supernatant was recorded at $570 \mathrm{~nm} .{ }^{30}$ The relative hemolytic rate (RHR\%) was calculated according to the following Equation 3:

$$
\mathrm{RHR} \%=\frac{\left(\mathrm{A}_{\text {sample }}-\mathrm{A}_{\mathrm{PBS}}\right)}{\left(\mathrm{A}_{\text {water }}-\mathrm{A}_{\mathrm{PBS}}\right)} \times 100 \%
$$




\section{In vitro Stability of THDR-NPs}

The stability of THDR-NPs was studied in PBS (pH 7.4, $0.01 \mathrm{M}$ ) containing $10 \% \mathrm{FBS}$ at $37^{\circ} \mathrm{C}^{29}$ Samples were taken at a set time point to measure the change of particle size by a Malvern particle size potentiometer to investigate the effect of physiological conditions on the stability of THDR-NPs.

\section{In vitro Drug Release}

The dialysis method was used to measure the release of DAS and ROZ in THDR-NPs through PBS solutions at different $\mathrm{pH}(\mathrm{pH} 6.0$ and 7.4, $0.01 \mathrm{M})$. In brief, $4 \mathrm{~mL}$ mixed micelles were transferred to a holding dialysis bag (MWCO $3.5 \mathrm{kDa}$ ), and afterwards immersed in $200 \mathrm{~mL}$ PBS $(0.01 \mathrm{M}, \mathrm{pH} 6.0$ or $\mathrm{pH} 7.4)$ containing $1 \%(\mathrm{w} / \mathrm{v})$ Tween 80 . At a predetermined time $(0 \mathrm{~h}, 0.5 \mathrm{~h}, 1 \mathrm{~h}, 2 \mathrm{~h}$, $4 \mathrm{~h}, 8 \mathrm{~h}, 12 \mathrm{~h}, 24 \mathrm{~h}, 36 \mathrm{~h}, 48 \mathrm{~h}), 1 \mathrm{~mL}$ of external buffer was taken out and replaced with the same volume of fresh buffer. The release profiles of DAS and ROZ at different $\mathrm{pH}$ were studied. The DAS and ROZ released by the drugloaded micelles were determined by high-performance liquid chromatography.

\section{In vitro Cytotoxicity}

The MTT method was used to detect the toxic effects of THDR-NPs, DAS and ROZ on different cancer cells. Briefly, MCF-7 cells $\left(5 \times 10^{3}\right)$ and MDA-MB-231 cells $\left(5 \times 10^{3}\right)$ in the logarithmic growth phase were seeded in 96-well plates. When the cell density reached about $70 \%$, the cell culture medium was replaced with a drugcontaining medium, which includes different concentrations of DAS, ROZ, DAS + ROZ, and THDR-NPs (using DAS concentration as the standard). After further incubation for $24 \mathrm{~h}$ or $48 \mathrm{~h}$, cell viability was determined by using the 3-(4,5-Dimethylthiazol-2-yl)-2,5-benzyltetrazolium bromide (MTT) assay method.

\section{Transwell Migration Experiment}

MCF-7 cells and MDA-MB-231 cells were cultured with different concentrations of DAS, ROZ, DAS + ROZ, and THDR-NPs for $24 \mathrm{~h}$. The cells were placed in serum-free medium, $200 \mu \mathrm{L}$ cell suspension $\left(1 \times 10^{5}\right.$ cells per well $)$ was added into the upper chamber of Transwell, and $600 \mu \mathrm{L}$ nutrient solution containing $10 \%$ FBS was added into the lower chamber followed by incubated in $37^{\circ} \mathrm{C}, 5 \% \mathrm{CO}_{2}$ for $24 \mathrm{~h}$. After washed with PBS ( $\mathrm{pH} 7.4,0.01 \mathrm{M}$ ) for three times, chamber was moved into $4 \%$ paraformaldehyde, fixed for $30 \mathrm{~min}$, and washed with PBS (pH 7.4, 0.01 M) for three times. Then, incubated with crystal violet staining solution for $15 \mathrm{~min}$, the excess crystal violet staining solution was removed with a cotton swab. Three visual fields were randomly observed under a microscope, and the number of cells passing through the membrane was counted.

\section{Cell Uptake Test}

MDA-MB-231 cells were seeded in 24-well plates at a density of $1 \times 10^{4}$ cells per well and cultured overnight. Then, separate them to three groups and treat with $\mathrm{C} 6$ (as a control), loaded C6 THD-NPs, loaded C6 TPGS-NPs (the drug is dissolved in serum-free medium), and cultured for $3 \mathrm{~h}^{30}$ The cells were washed with PBS (pH 7.4, 0.01 $\mathrm{M}$ ), and the nucleus were stained with DAPI for $10 \mathrm{~min}$, the cells were imaged using fluorescence microscopy.

\section{Plasma Pharmacokinetics}

Female SD rats (5 mice in each group) were intraperitoneally injected with DAS + ROZ and THDR-NPs at a DAS dose of $5 \mathrm{mg} / \mathrm{kg}$. A $0.3 \mathrm{~mL}$ of blood samples was collected at different time points $(0 \mathrm{~min}, 2 \mathrm{~min}, 5 \mathrm{~min}, 10 \mathrm{~min}, 20 \mathrm{~min}$, $40 \mathrm{~min}, 1 \mathrm{~h}, 2 \mathrm{~h}, 4 \mathrm{~h}, 6 \mathrm{~h}, 8 \mathrm{~h}, 12 \mathrm{~h}, 24 \mathrm{~h}$ ) and centrifuged at $4000 \mathrm{rpm}$ for $10 \mathrm{~min}$ to get the supernatant. Methanol (300 $\mu \mathrm{L})$ and diclofenac sodium as an internal standard $(10 \mu \mathrm{L})$ were added to $100 \mu \mathrm{L}$ of plasma, and the sample was centrifuged at $5000 \mathrm{rpm}$ for $10 \mathrm{~min}$. The supernatant was collected for HPLC analysis to calculate the drug concentration in rats at each time point, the pharmacokinetic parameters were analyzed through the WinNonlin 8.2 software.

\section{In vivo Imaging Study}

In order to evaluate the tumor targeting of nanomedicine, a mouse model of xenograft derived from MDA-MB-231 cells was established by subcutaneously injecting $2 \times 10^{7}$ MDA-MB-231 cells into the right side of mice. When the tumor grows to about $500 \mathrm{~mm}^{3}$, the mice were randomly divided into two groups ( 3 in each group). The fluorescent dye $\mathrm{Cy} 3^{31}$ was assembled into a nanoparticle system to track the distribution of nanomedicine in vivo. Mice were injected with free $\mathrm{Cy} 3, \mathrm{Cy} 3-\mathrm{THD}-\mathrm{NPs}$ through the tail vein, and the dose of Cy3 was $10 \mu \mathrm{g}$ per mouse. In vivo imaging was performed on a small animal in vivo imager $1 \mathrm{~h}, 4 \mathrm{~h}, 8 \mathrm{~h}$ and $24 \mathrm{~h}$ after injection.

\section{In vivo Antitumor Efficiency}

The $2 \times 10^{7}$ MDA-MB-231 cells were inoculated subcutaneously on the right side of BALB/C nude mice (4-5 weeks 
old, female) to establish tumor-bearing mice model. ${ }^{32}$ In order to evaluate the therapeutic effect in vivo, the mice were divided into 5 groups (normal saline group, DAS group, ROZ group, DAS + ROZ group, and micellar group). When the tumor size was increased to about $100 \mathrm{~cm}^{3}$, normal saline, DAS, ROZ, DAS + ROZ, and THDR-NPs $(5 \mathrm{mg} / \mathrm{kg})$ were intraperitoneal inject to mice groups, respectively. The administrations were performed seven times every three days, the changes in tumor size and body weight over time were measured. The tumor volume (V) was calculated according to Equation 4:

$$
\mathrm{V}=(\text { tumor length }) \times(\text { tumor width })^{2} / 2
$$

After the experiment was completed, the mice were euthanized. The tumor tissues and major organs, including the heart, liver, spleen, lung and kidney were taken out, after H\&E staining, they were further studied with a microscope.

\section{Results and Discussion \\ Synthesis and Characterization of HA-DAS Polymer}

The synthesis of tailored amphiphilic polymer employed the typical esterification method. As shown in Figure 1, the polymer was analyzed by proton nuclear magnetic resonance with heavy water as solvent. Among them, $\delta$ $1.91 \mathrm{ppm}, \delta 3.23-4.44 \mathrm{ppm}, \delta 5.06 \mathrm{ppm}$ and $\delta 5.79 \mathrm{ppm}$ are the proton peaks on HA. $\delta 2.77 \mathrm{ppm}$ and $\delta 3.10 \mathrm{ppm}$ are the proton peaks of DAS phenyl and pyrimidinyl methyl groups, respectively. The proton peaks on DAS piperazine ethyl are at 2.97-3.08 ppm, and the proton peaks on DAS pyrimidinyl and thiazolyl are at $\delta 6.77$ ppm and $\delta 7.89$ ppm, respectively. In addition, the chemical shift of the proton peak on the piperazine ethyl group of DAS was increased, indicating that DAS has been successfully combined with HA through the ester bond, and DAS-HA polymer was successfully prepared.

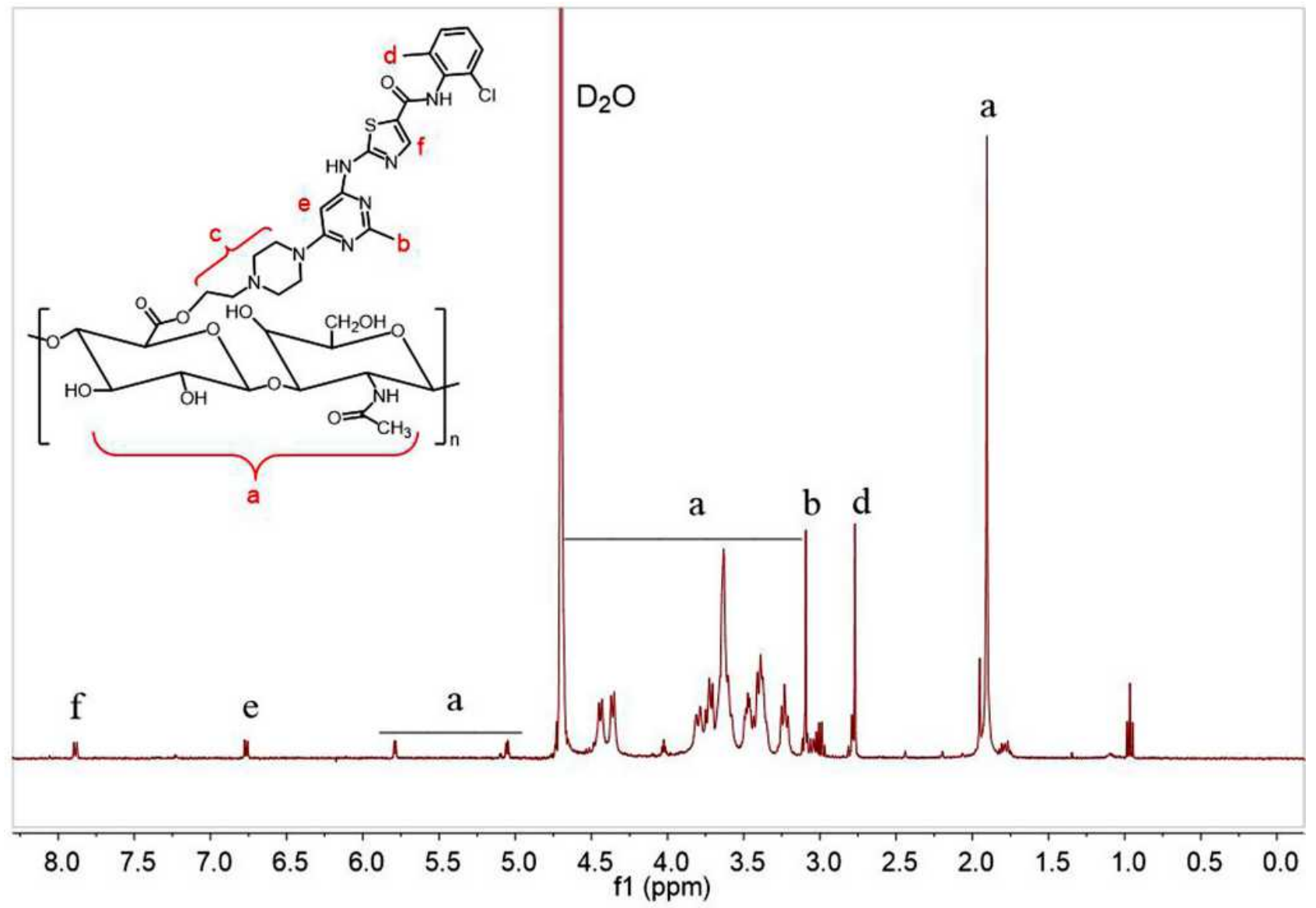

Figure I ' $\mathrm{H}$ NMR characterization of HA-DAS polymer, each letter represents a different proton in the HA-DAS polymer. The 'H NMR spectrum is measured in $\mathrm{D}_{2} \mathrm{O}$. Abbreviations: $\mathrm{D}_{2} \mathrm{O}$, deuterium generation of water; NMR, nuclear magnetic resonance; DAS, dasatinib; HA, hyaluronic acid. 


\section{Characterization}

HA-DAS and TPGS are amphiphilic substances and both have hydrophilic ends and lipophilic parts, which can selfassemble to form micelle system in aqueous solution. The morphology, particle size, zeta potential and PDI of THDRNPs were analyzed by transmission electron microscope and Malvern Zetasizer Nano ZSE. As shown in Figure 2 and Table 1, the particle size was $63.31 \pm 3.71 \mathrm{~nm}(\mathrm{n}=3)$, the Zeta potential was $-3.297 \pm 1.029 \mathrm{mV}$, the particle size was uniform. TEM images also show that THDR-NPS has good monodispersion and is spherical in shape. The DL of DAS was $1.34 \% \pm 0.15 \%$, the DL and EE of ROZ were $6.33 \% \pm$ $0.35 \%$ and $69.67 \% \pm 3.89 \%$, respectively.

After intravenous injection, THDR-NPs will be diluted in the bloodstream and needs to be preserved for structural integrity. Therefore, it is necessary to evaluate the dilution stability of the THDR-NPs. The CMC of THDR-NPs

\section{A}

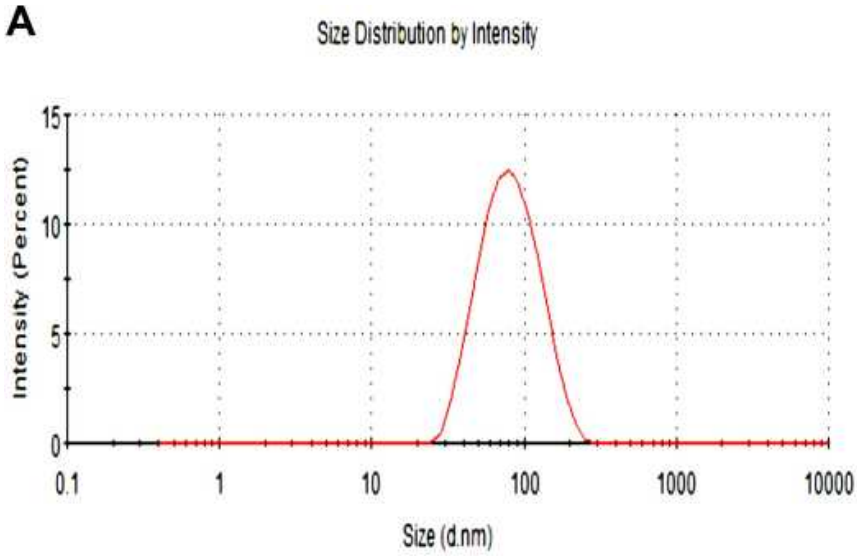

C

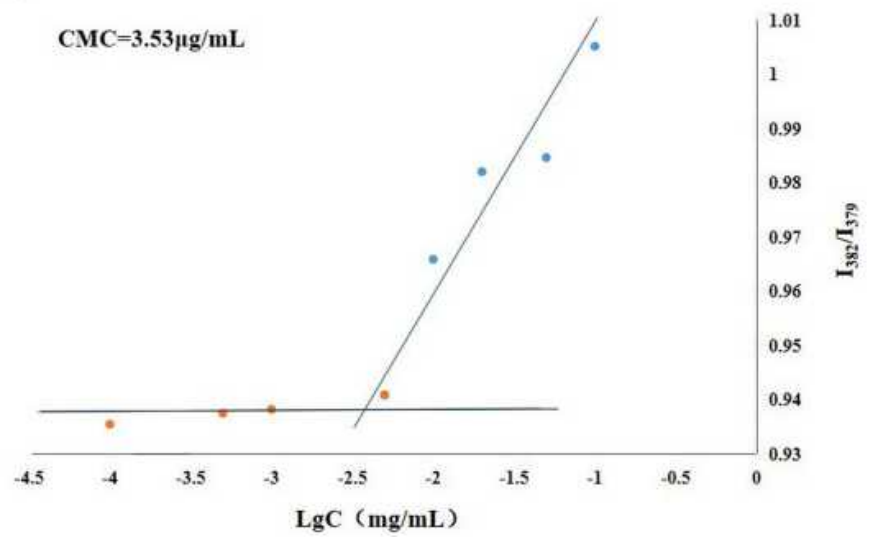

calculated was $3.53 \mu \mathrm{g} / \mathrm{mL}$ (Figure $2 \mathrm{C}$ ), indicating that it has anti-dilution ability.

The stability of THDR-NPs is of great significance for maintaining the structural integrity of the drug delivery process. Therefore, it is necessary to investigate the stability of drug-loaded micelles under physiological conditions in vivo. In this experiment, PBS solution ( $\mathrm{pH} 7.4,0.01 \mathrm{M}$ ) containing $10 \%$ FBS was used to simulate the microenvironment of the systemic circulation, and the particle size changes of THDRNPs were investigated to evaluate the stability of the nanoparticle. As shown in Figure 2D, the particle size of THDRNPs in the medium fluctuates slightly, indicating that the stability of the THDR-NPs prepared in this study is better.

\section{Hemolysis Test}

Hemolysis is a phenomenon in which red blood cells rupture and dissolve. Some drugs contain hemolytic components or
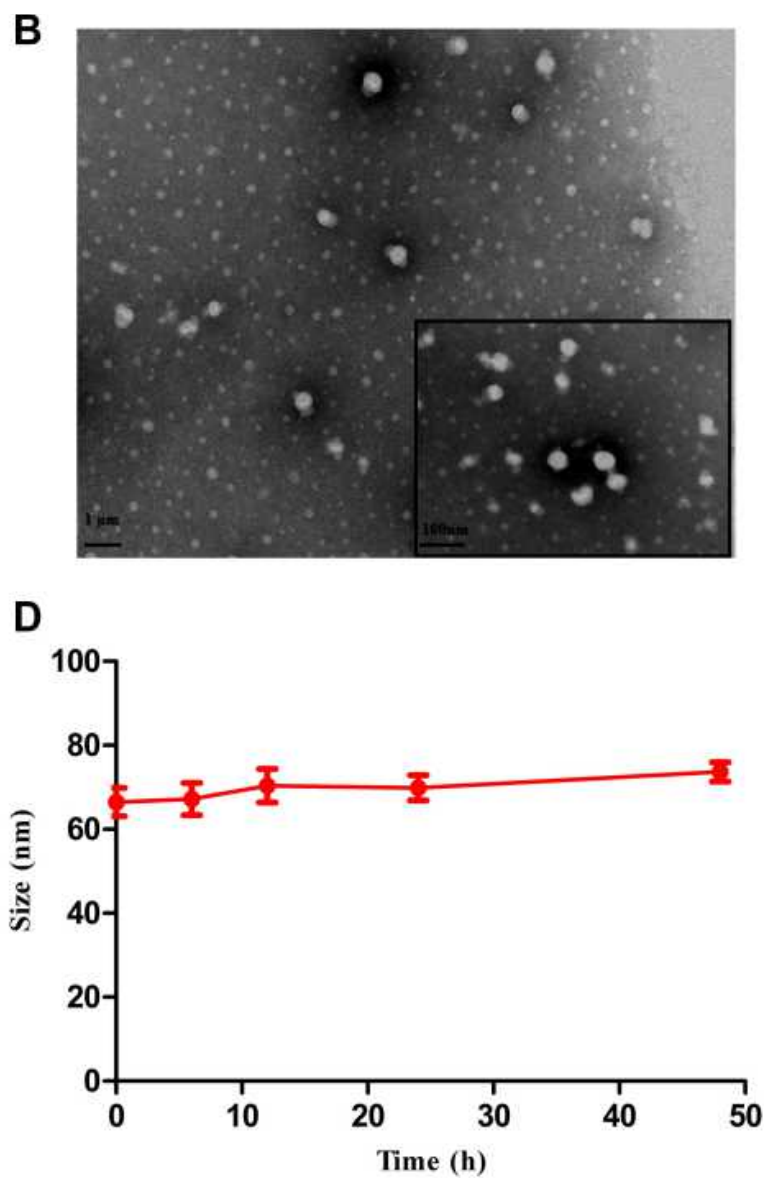

Figure 2 (A) The particle size distribution of THDR-NPs measured by DLS. (B) TEM image of THDR-NPs using negative staining. (C) CMC of THDR-NPs measured by Fluorescence spectrophotometer. (D) Size changes of THDR-NPs over the course of 48 hours, indicating the stability of the NPs.

Abbreviations: DLS, dynamic light scattering; TEM, transmission electron microscopy; CMC, critical micelle concentration; THDR-NPs, HA-DAS and TPGS mixed micelle system loaded with ROZ. 
Table I Sizes, Zeta Potentials DL and EE of the THDR-NPs

\begin{tabular}{|l|c|c|c|c|c|}
\hline Size(nm) & PDI & Zeta Potential (mV) & DL/DAS (\%) & DL/ROZ (\%) & EE/ROZ (\%) \\
\hline $63.31 \pm 3.71$ & $0.310 \pm 0.44$ & $-3.297 \pm 1.029$ & $1.34 \pm 0.15$ & $6.33 \pm 0.35$ & $69.67 \pm 3.89$ \\
\hline
\end{tabular}

Note: The results are expressed as the mean $\pm S D, n=3$.

Abbreviations: PDI, polydispersity index; DL, drug loading; EE, encapsulation efficiency; DAS, dasatinib; ROZ, rosiglitazone; THDR-NPs, HA-DAS and TPGS mixed micelle system loaded with ROZ.

may give rise to red blood cell aggregation to cause obstacles to the blood system, so safety investigations on injections are required. As shown in Figure 3, THDR-NPs of different concentrations did not show hemolysis phenomenon, indicating that the safety of each preparation is convincible and can be used for injection administration.

\section{In vitro Drug Release Study}

PBS solution ( $\mathrm{pH} 6.0$ and $7.4,0.01 \mathrm{M}$ ) was used to simulate the physiological conditions to study the drug release of THDR-NPs in PBS solution at different $\mathrm{pH}$. It can be seen from Figure 4A that when the PBS solution $\mathrm{pH}$ is 7.4 , about $43 \%$ of DAS was released from THDRNPs, and about $50 \%$ of ROZ was released from THDRNPs at $48 \mathrm{~h}$. Under weakly acidic conditions (pH 6.0), the release of DAS increased to about $60 \%$ and the release of ROZ increased to about $73 \%$ within $48 \mathrm{~h}$ (Figure $4 \mathrm{~B}$ ). As mentioned above, the $\mathrm{pH}$ of the tumor site was lower than the normal physiological environment ( $\mathrm{pH}$ 7.4). The ester bond connecting DAS and HA is sensitive to weak acid
A

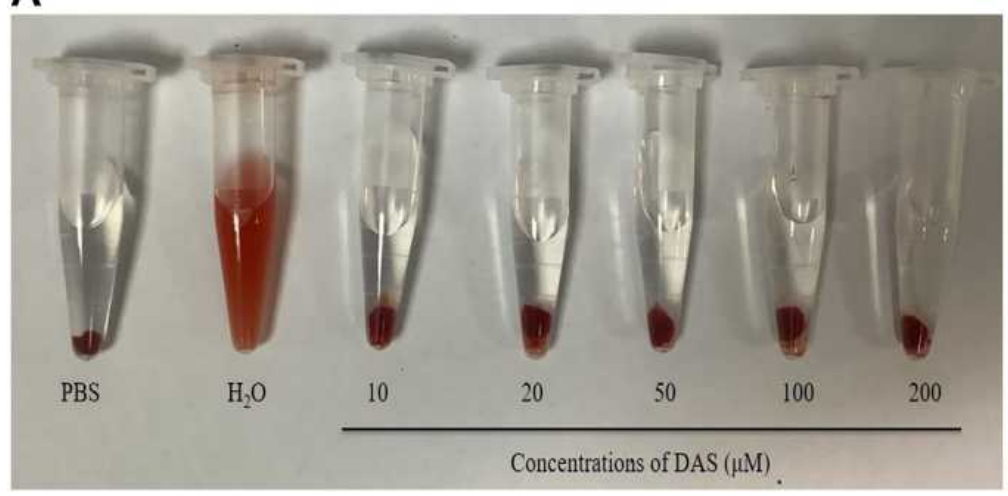

B

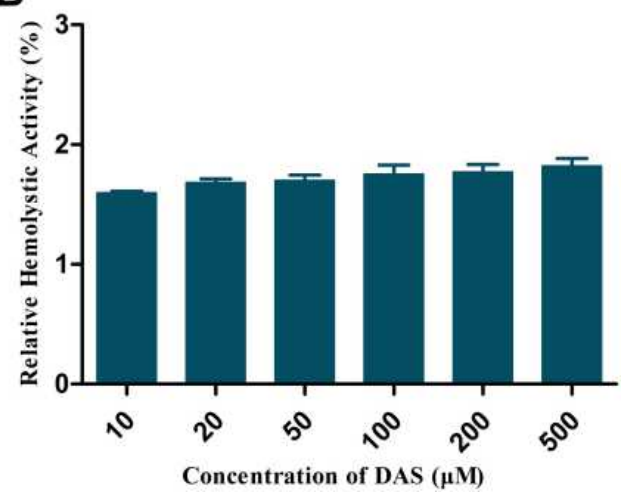

Figure 3 (A) Photographs of the RBC hemolysis assay of THDR-NPs with different DAS concentrations, using normal PBS and water as the negative and positive controls. (B) Hemolysis rates of THDR-NPs with different DAS concentrations.

Note: The results are expressed as the mean \pm SD, $n=3$.

Abbreviations: RBC, red blood cells; DAS, dasatinib; THDR-NPs, HA-DAS and TPGS mixed micelle system loaded with ROZ.

A

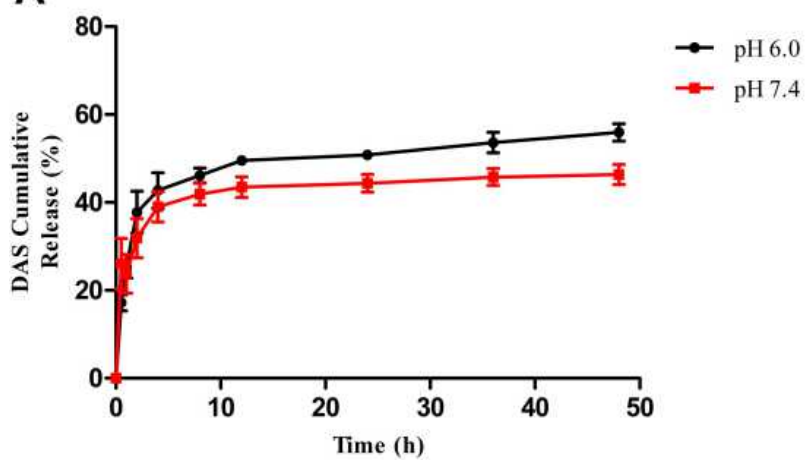

B

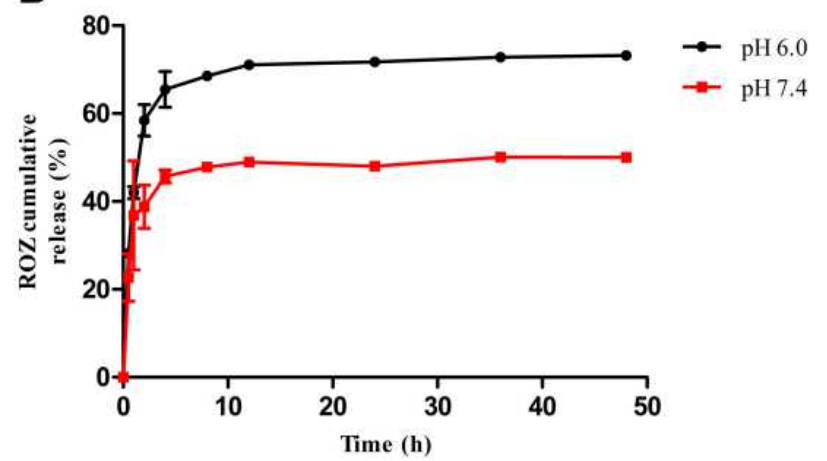

Figure 4 Cumulative DAS release profiles from THDR-NPs (A) and ROZ release profiles from THDR-NPs (B). PBS containing I\% (w/v) Tween 80 and different pH (6.0, 7.4) was used as the release medium.

Note: The results are expressed as the mean $\pm S D, n=3$.

Abbreviations: DAS, dasatinib; ROZ, rosiglitazone; THDR-NPs, HA-DAS and TPGS mixed micelle system loaded with ROZ. 
environment, in which case the ester bond will be broken. With the change of micellar structure, the release of DAS and ROZ was accelerated, which can avoid the premature release of the drug in the body and achieve the effect of sustained release.

\section{In vitro Cytotoxicity Study}

In vitro cytotoxicities of DAS, ROZ, DAS + ROZ, THDR-NPs were measured via MTT assay using MDA-MB-231 cells and MCF-7 cells. It can be seen from Figure 5 that after $24 \mathrm{~h}$ of incubation, ROZ had no obvious toxic effect on both cells, the cell survival rate is higher than $90 \%$. After the two drugs were used in combination, at low concentrations, the toxic effect on cells is lower than that of free DAS. It exhibits strong toxic effects, and the cytotoxicity of THDRNPs to both cells is significantly stronger than the combined use of the two drugs $(p<0.05)$. After 48 $\mathrm{h}$ of incubation, the trend was similar to that of $24 \mathrm{~h}$, but the cytotoxicity was significantly enhanced, indicating that the cytotoxicity of the preparation was concentration-dependent and time-dependent. Table 2 summarizes the $\mathrm{IC}_{50}$ values of various drugs acting on cells at different times $(24 \mathrm{~h}, 48 \mathrm{~h})$. As shown in Table 2, the $\mathrm{IC}_{50}$ of THDR-NPs in different cells is less than DAS + ROZ, indicating that the cytotoxic effect on the two cells has increased after being formed into THDR-NPs. And with the extension of the treatment time, the difference in $\mathrm{IC}_{50}$ between THDR-NPs and DAS + ROZ in different cells also increased significantly $(p<0.05)$. These results indicate that DAS and ROZ can be prepared into THDR-NPs to increase the toxic effect on tumor cells.

\section{Transwell Cell Migration Experiment}

MTT results show that ROZ has no significant cytotoxicity $(p>0.05)$ to two cells within $24 \mathrm{~h}$ (Figure $6 \mathrm{~A})$, but the number of cells penetrating the membrane was significantly reduced, indicating that $\mathrm{ROZ}$ has a good inhibitory effect on the metastasis of these two kinds of cells (Figure 6B). The inhibitory effect of ROZ on cell migration was consistent with the experimental hypothesis. In the Transwell cell migration experiment (Figure 7A and B), after being treated with different drugs (DAS, ROZ, DAS + ROZ, THDRNPs) at different concentrations for $24 \mathrm{~h}$, the numbers of MCF-7 cells and MDA-MB-231 cells passing through the membrane decreased with the increase of the drug concentration. As shown in Figure $7 \mathrm{C}$ and D, compared to the free drugs, THDR-NPs can better inhibit the migration ability of cells at different concentrations $(p<0.05)$, as well as the possibility of
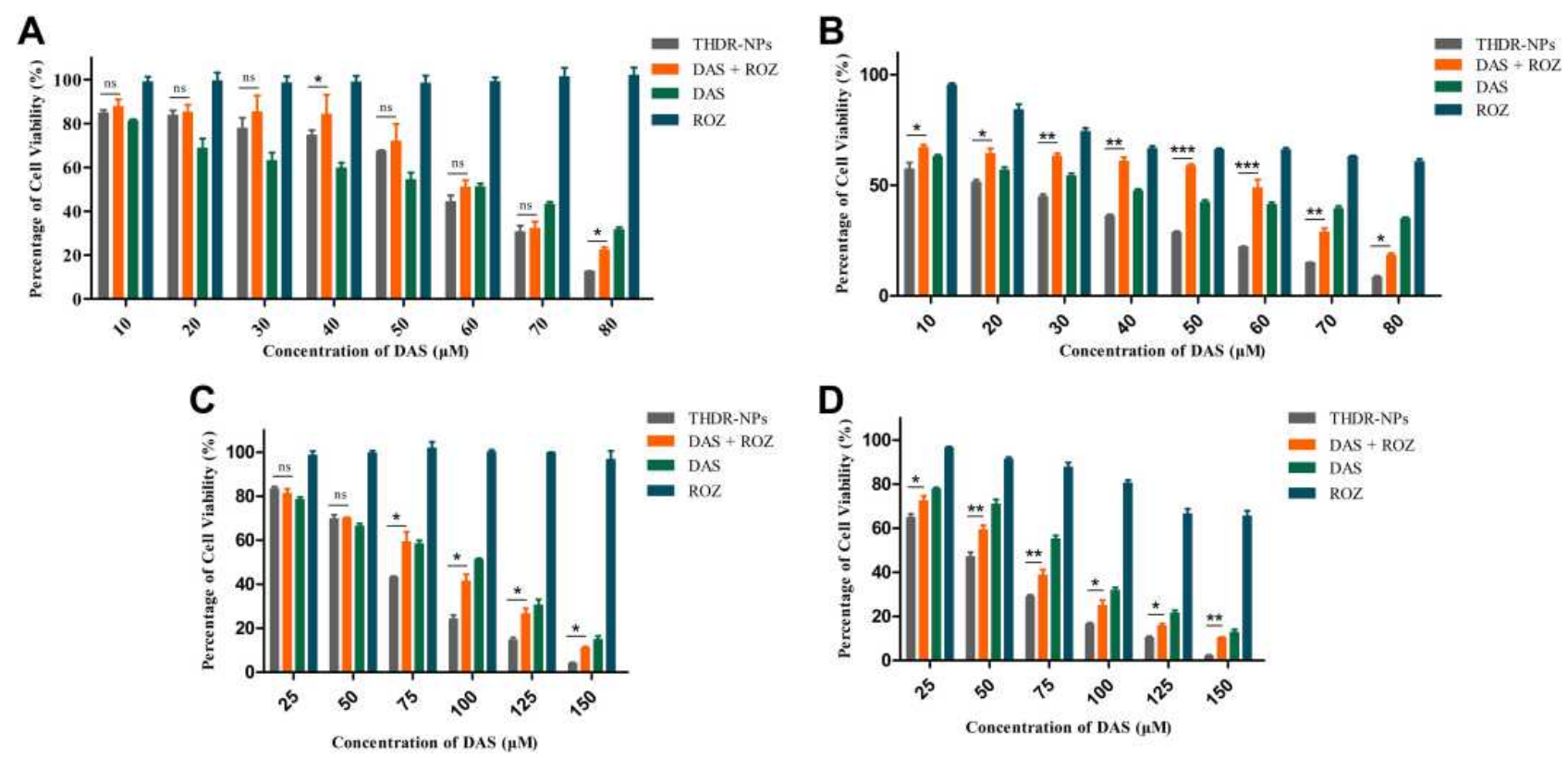

Figure 5 In vitro cytotoxicity analysis of MCF-7 cells after $24 \mathrm{~h}(\mathbf{A})$ and $48 \mathrm{~h}(\mathbf{B})$ treatment and MDA-MB-23I cells after $24 \mathrm{~h}(\mathbf{C})$ and $48 \mathrm{~h}(\mathrm{D})$ treatment with free DAS, ROZ, DAS+ROZ and THDR-NPs. The cell viabilities were determined by MTT cytotoxicity assay.

Notes: The results are expressed as the mean $\pm S D, n=3$. "ns" to indicate no significance $(p>0.05),{ }^{*} p<0.05$, $* * p<0.01$, and $* * * p<0.001$.

Abbreviations: DAS, dasatinib; ROZ, rosiglitazone; THDR-NPs, HA-DAS and TPGS mixed micelle system loaded with ROZ. 
Table 2 In vitro Cytotoxicity of MCF-7 Cells and MDA-MB-23I Cells After $24 \mathrm{~h}$ and $48 \mathrm{~h}$ Incubation with Different Drug Formulations as Determined by MTT Assay

\begin{tabular}{|l|c|c|c|c|}
\hline \multirow{2}{*}{ Groups } & \multicolumn{4}{|c|}{ IC $_{\mathbf{5 0}}(\mu \mathrm{M})$} \\
\cline { 2 - 5 } & \multicolumn{2}{|c|}{ MCF-7 Cells } & $\mathbf{2}$ & MDA-MB-23 I Cells \\
\cline { 2 - 5 } & $\mathbf{2 4}$ & $\mathbf{4 8} \mathbf{h}$ & $\mathbf{4 8} \mathbf{h}$ \\
\hline THDR-NPs & $49.93 \pm 4.68$ & $18.57 \pm 1.79$ & $58.33 \pm 2.15$ & $40.94 \pm 1.89$ \\
DAS+ROZ & $66.22 \pm 15.08$ & $40.39 \pm 4.83 *$ & $70.22 \pm 4.95 * *$ & $51.37 \pm 0.44 * *$ \\
DAS & $51.98 \pm 6.83$ & $31.19 \pm 2.8$ & $73.63 \pm 3.8$ & $64.67 \pm 2.63$ \\
ROZ & NA & $102.06 \pm 6.2$ & NA & $258.95 \pm 27.53$ \\
\hline
\end{tabular}

Notes: The results are expressed as the mean $\pm \mathrm{SD}, \mathrm{n}=3 . *_{p}<0.05, * *_{p}<0.01$ (THDR-NPs vs DAS+ROZ).

Abbreviations: DAS, dasatinib; ROZ, rosiglitazone; THDR-NPs, HA-DAS and TPGS mixed micelle system loaded with ROZ.

tumor metastasis, and treat tumors with more efficiency. In addition, it can be found that the membrane penetration number of MDA-MB-231 cells is $1259 \pm$ 76 , and that of MCF-7 cells is $509 \pm 44$, indicating that the transferability of MAD-MB-231 cells is higher than that of MCF-7 cells $(p<0.05)$. Therefore, MDA-MB -231 cells are selected for subsequent experiments.

\section{Cellular Uptake}

We studied the cellular uptake of MDA-MB-231 cells through fluorescence microscopy. Figure 8 shows that after $3 \mathrm{~h}$ of incubation, compared with cells treated with micelles without HA, the cells treated with micelles containing HA showed more C6 fluorescence. The results further indicate that introducing HA which is the most important ligand for

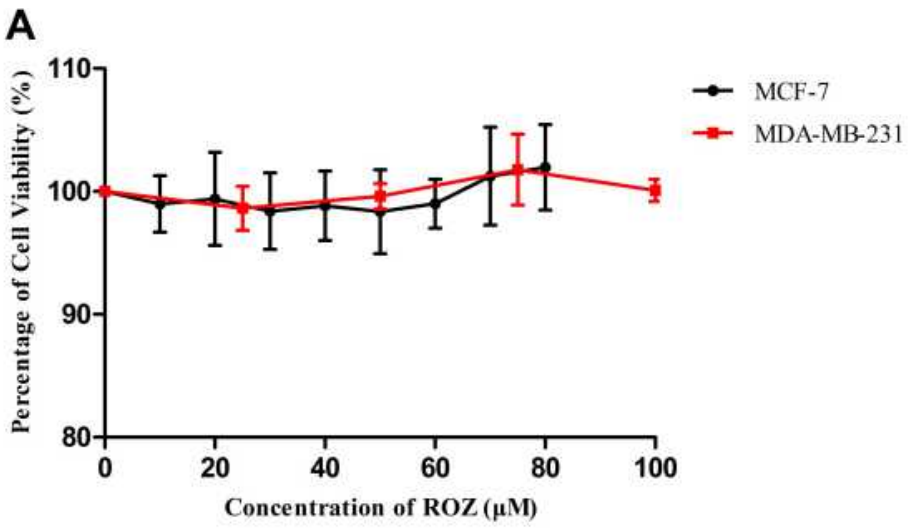

B

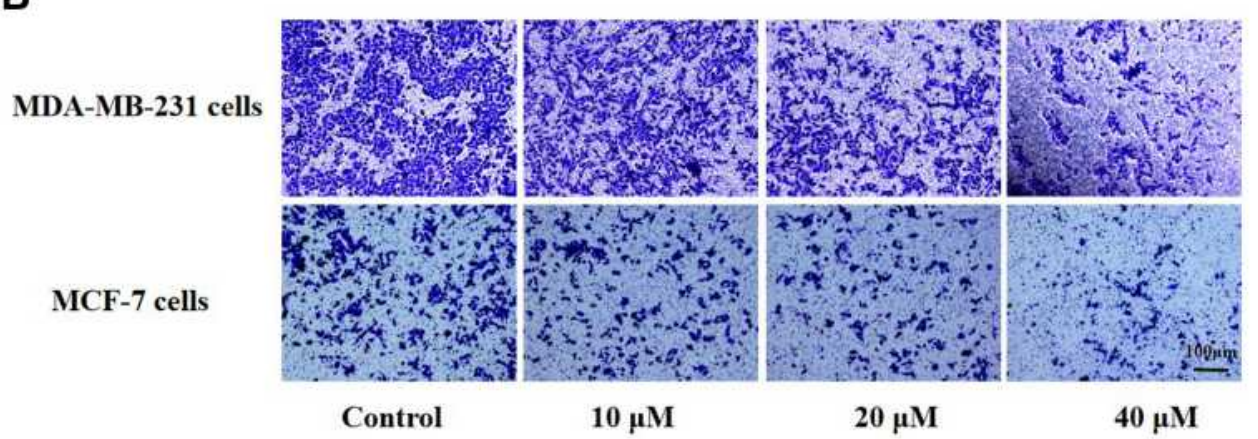

Figure 6 (A) In vitro cytotoxicity analysis of MCF-7 cells and MDA-MB-23I cells treatment with various concentrations of ROZ. The cell viabilities were determined by MTT cytotoxicity assay. (B) Transwell cell migration experiment of MCF-7 cells and MDA-MB-23I cells treated with different concentrations of ROZ.

Notes: The results are expressed as the mean $\pm S D, n=3$. Scale bar $=100 \mu \mathrm{m}$.

Abbreviations: DAS, dasatinib; ROZ, rosiglitazone; THDR-NPs, HA-DAS and TPGS mixed micelle system loaded with ROZ. 

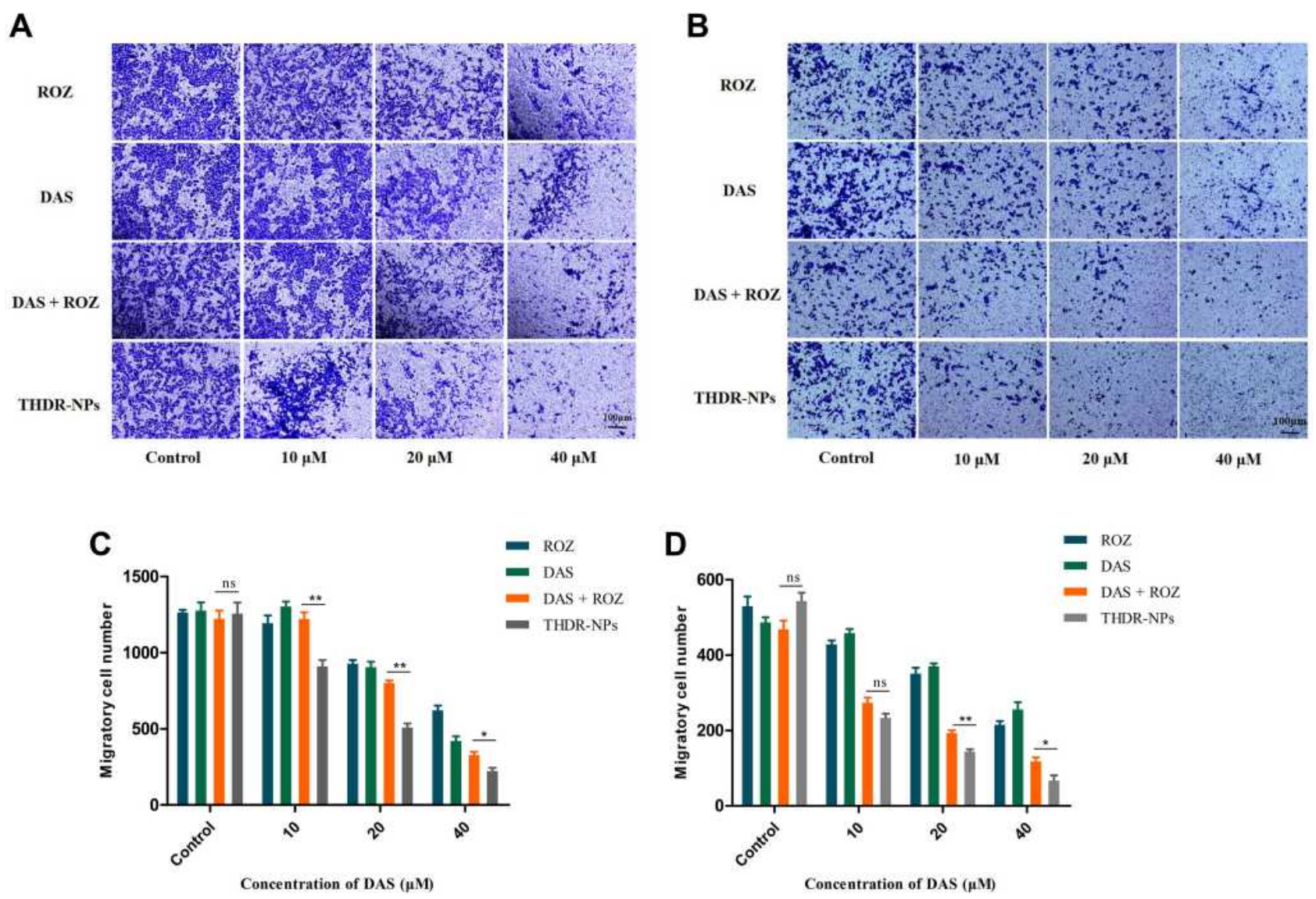

Figure 7 Transwell cell migration experiment of MDA-MB-23I cells (A) and MCF-7 cells (B) treated with free DAS, ROZ, DAS+ROZ and THDR-NPs, and observe through a microscope. The quantification of the number of migrated cells of MDA-MB-23I cells (C) and MCF-7 cells (D) treated with free DAS, ROZ, DAS+ROZ and THDR-NPs. Notes: The results are expressed as the mean \pm SD, $n=3$. "ns" to indicate no significance $(p>0.05), *_{p}<0.05,{ }^{* *} p<0.01$. Scale bar $=100 \mu$ m.

Abbreviations: DAS, dasatinib; ROZ, rosiglitazone; THDR-NPs, HA-DAS and TPGS mixed micelle system loaded with ROZ.

CD44 protein into the micelle can increase the absorption of C6 by tumor cells, which can make THDR-NPS have better targeting and stronger cytotoxicity.

\section{In vivo Pharmacokinetic Study}

The results obtained from the pharmacokinetic study are shown in Figure 9 and Table 3. It can be seen that the pharmacokinetic parameters such as AUC, MRT and Cmax of the THDR-NPs group are significantly different from those of the free DAS group $(p<0.05)$ (Table $3 \mathrm{~A}$ ). $\mathrm{AUC}_{0-\infty}$ of the THDR-NPs group was 3.96 folds that of the free DAS group, indicating that the drug content in the plasma was significantly increased, which improves the bioavailability of DAS. The $\mathrm{MRT}_{0-\infty}$ of the THDR-NPs group was 5.01 folds that of the free DAS group, indicating that DAS encapsulated in nanoparticles can significantly increase the circulation time of dasatinib in the body and increase the retention efficiency of DAS. Moreover, the pharmacokinetic parameters of ROZ were changed (Table $3 \mathrm{~B})$. The $\mathrm{MRT}_{0-\infty}$ of the THDR-NPs group is 1.46 folds that of the free ROZ group, the Tmax and $t_{1 / 2}$ of the THDR-NPs group are 2.5 folds and 1.79 folds that of the free $\mathrm{ROZ}$ group, respectively. $\mathrm{ACU}_{0-\infty}$ is also higher than the free ROZ group, and the drug content in plasma increases. It shows that DAS and ROZ loaded in THDR-NPs can make the drug be absorbed at a higher concentration and have a stronger systemic effect.

\section{In vivo Biodistribution Study}

In order to further study the targeting effect of THDRNPs in vivo, we modified the nanoparticles with the dye $\mathrm{Cy} 3$ to explore whether the nanoparticles 


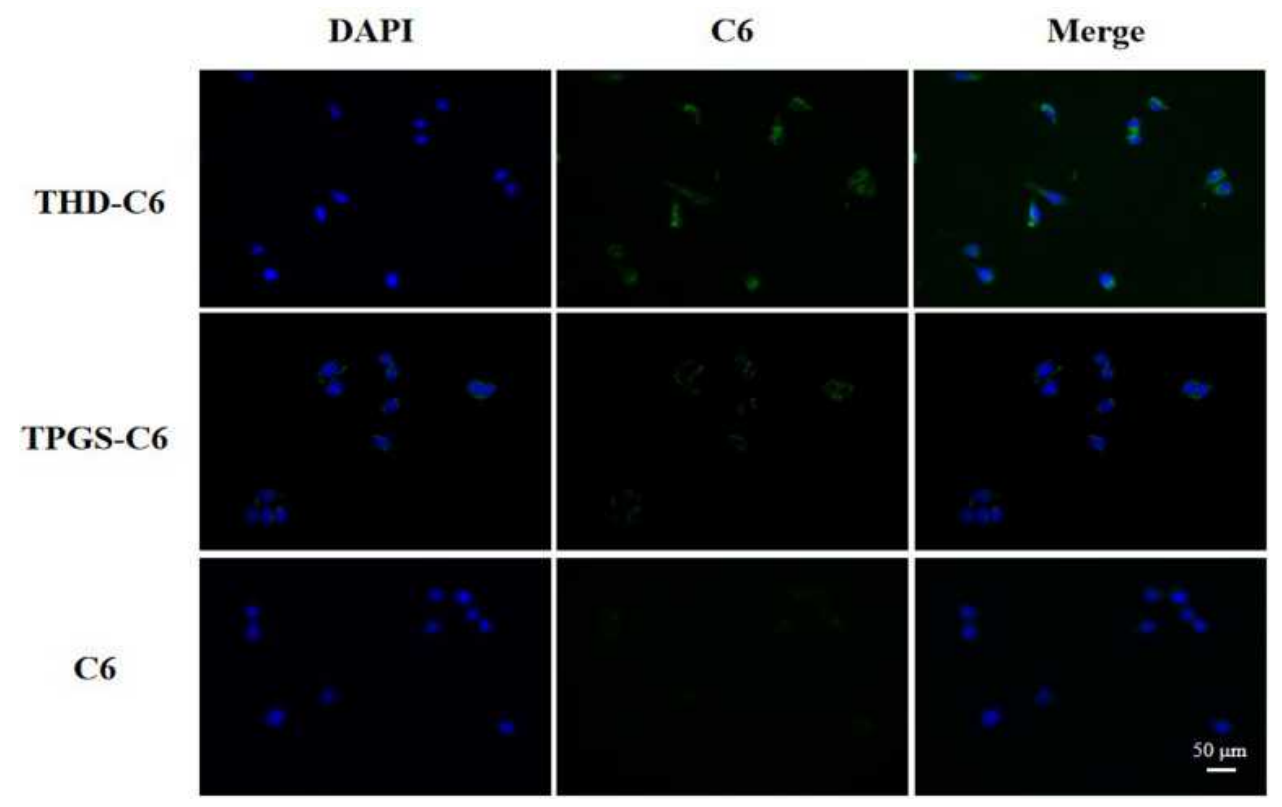

Figure 8 Cellular uptake of THDR-NPs in MDA-MB-23I cells investigated via fluorescence microscopy. Note: Scale bar $=50 \mu \mathrm{m}$.

Abbreviations: TPGS-C6, TPGS loaded C6 micelles; THD-C6, HA-DAS and TPGS mixed micelle system loaded with C-6; THDR-NPs, HA-DAS and TPGS mixed micelle system loaded with ROZ.
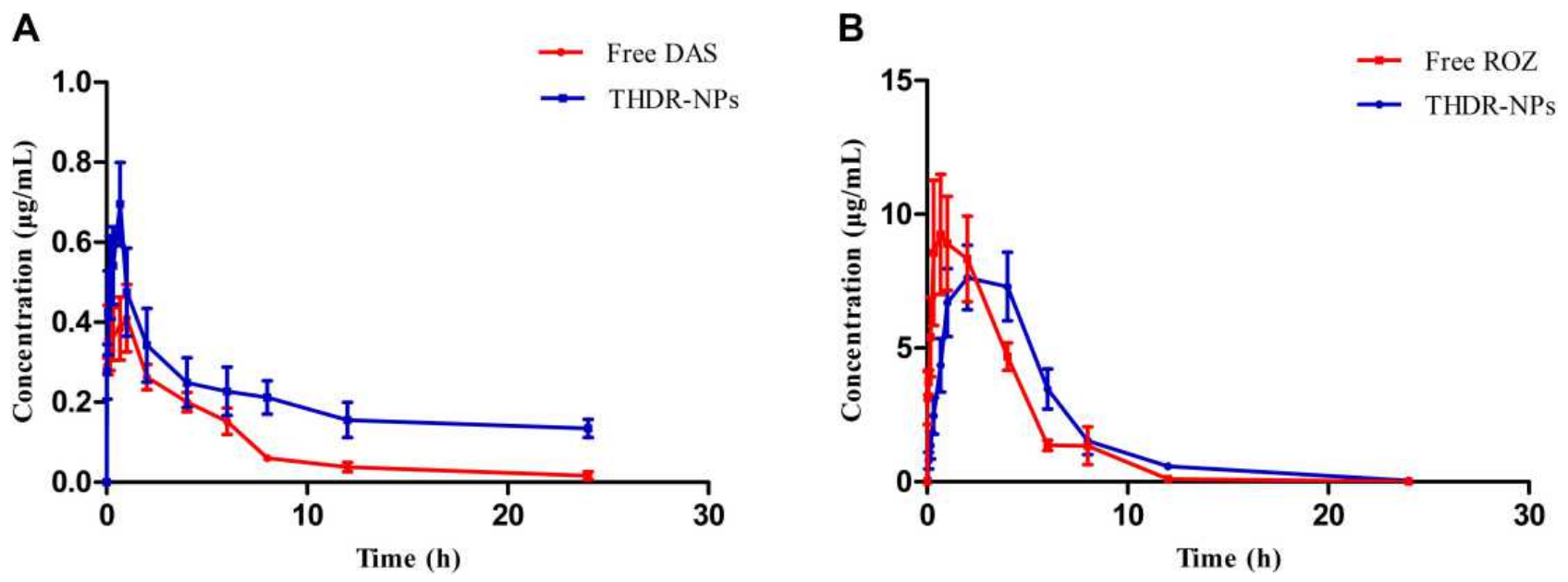

Figure 9 The drug-time curve of SD rats after intraperitoneal injection of THDR-NPs and DAS+ROZ ( $\mathrm{n}=5)$, the drug-time curve of DAS (A) and ROZ (B) in SD rats. Notes: The results are expressed as the mean $\pm S D, n=3$.

Abbreviations: DAS, dasatinib; ROZ, rosiglitazone; THDR-NPs, HA-DAS and TPGS mixed micelle system loaded with ROZ.

accumulate in the tumor site and retention time of the drug in the body is prolonged. Results measured by fluorescent imaging technology at 1, 4, 8 and $24 \mathrm{~h}$ after the tail vein injection are shown in Figure 10. The fluorescence signal of free $\mathrm{Cy} 3$ at the tumor site is much lower than that of Cy3-THD-NPs, which means that nanoparticles have a good ability to accumulate at the tumor site. In contrast, the fluorescence signal of 
Table 3 The Pharmacokinetic Parameters of DAS (A) and ROZ (B) in SD Rats Plasma After Intraperitoneal Injection of THDRNPs and DAS + ROZ in SD Rats

\begin{tabular}{|c|c|c|}
\hline \multicolumn{3}{|c|}{ A } \\
\hline \multirow[t]{2}{*}{ PK Parameters } & \multicolumn{2}{|c|}{ Groups } \\
\hline & Free DAS & THDR-NPs \\
\hline $\begin{array}{l}\mathrm{AUC}_{0-24}[\mu \mathrm{g} / \\
(\mathrm{mL} \cdot \mathrm{h})]\end{array}$ & $2.26 \pm 0.93$ & $9.44 \pm 2.32 *$ \\
\hline $\begin{array}{l}A \cup C_{0-\infty}[\mu g / \\
(m L \cdot h)]\end{array}$ & $2.38 \pm 1.12$ & $9.44 \pm 4.00^{* *}$ \\
\hline $\mathrm{MRT}_{0-24}(\mathrm{~h})$ & $5.06 \pm 0.94$ & $9.39 \pm 1.00^{* *}$ \\
\hline$M R T_{0-\infty}(h)$ & $6.08 \pm 2.03$ & $30.47 \pm 17.04^{* *}$ \\
\hline$T_{\max }(h)$ & $0.62 \pm 0.41$ & $0.73 \pm 0.15$ \\
\hline $\mathrm{C}_{\max }(\mu g / \mathrm{mL})$ & $0.44 \pm 0.17$ & $0.76 \pm 0.22^{*}$ \\
\hline $\mathrm{t}_{1 / 2}(\mathrm{~h})$ & $4.38 \pm 1.22$ & $29.19 \pm 8.68^{* *}$ \\
\hline \multicolumn{3}{|l|}{ B } \\
\hline \multirow[t]{2}{*}{ PK Parameters } & \multicolumn{2}{|c|}{ Groups } \\
\hline & Free ROZ & THDR-NPs \\
\hline $\begin{array}{l}\mathrm{AUC}_{0-24}[\mu \mathrm{g} / \\
(\mathrm{mL} \cdot \mathrm{h})]\end{array}$ & $41.06 \pm 10.85$ & $47.56 \pm|7.2|$ \\
\hline $\begin{array}{l}\mathrm{AUC}_{0_{-\infty}[\mu \mathrm{g} /} \\
(\mathrm{mL} \cdot \mathrm{h})]\end{array}$ & $41.34 \pm 10.68$ & $48.69 \pm 17.86$ \\
\hline $\mathrm{MRT}_{0-24}(\mathrm{~h})$ & $3.04 \pm 0.79$ & $4.23 \pm 0.73$ \\
\hline $\mathrm{MRT}_{0-\infty}(\mathrm{h})$ & $3.14 \pm 0.77$ & $4.57 \pm 0.70^{\circ}$ \\
\hline$T_{\max }(h)$ & $0.80 \pm 0.69$ & $2.00 \pm 1.22$ \\
\hline $\mathrm{C}_{\max }(\mu \mathrm{g} / \mathrm{mL})$ & $11.43 \pm 3.79$ & $8.67 \pm 3.05$ \\
\hline$t_{1 / 2}(h)$ & $1.60 \pm 0.38$ & $2.87 \pm 0.96^{\circ}$ \\
\hline
\end{tabular}

Notes: The results are expressed as the mean $\pm S D, n=5 . * p<0.05$, **p $<0.01$ (DAS in THDR-NPs vs free DAS), ${ }^{\wedge}<0.05$ (ROZ in THDR-NPs vs free ROZ). Abbreviations: $\mathrm{AUC}_{0-24}$, area under the plasma concentration-time curve from time $0 \mathrm{~h}$ to $24 \mathrm{~h}$ of quantifiable concentration; $\mathrm{AUC}_{0-\infty}$, area under the plasma concentration-time curve from time 0 extrapolated to infinite time; $\mathrm{MRT}_{0-24}$, mean residence time of a drug molecule $0 \mathrm{~h}$ to $24 \mathrm{~h} ; \mathrm{MRT}_{0-\infty}$, mean residence time of a drug molecule from time 0 extrapolated to infinite time; $T_{\max }$, time to reach maximum concentration; $C_{\max }$, the maximum peak time; $t_{1 / 2}$, elimination half-life; DAS, dasatinib; ROZ, rosiglitazone; THDR-NPs, HA-DAS and TPGS mixed micelle system loaded with ROZ.

mice receiving free $\mathrm{Cy} 3$ decayed rapidly after the early time point, and no significant accumulation was observed in the tumor.

\section{In vivo Antitumor Efficacy}

Finally, we studied the therapeutic effects of various drugs on the BALB/c nude mice model of MDA-MB
-231 cell ectopic colonization tumor $(n=5)$. The free DAS and the free DAS + ROZ treatment group have similar effects in inhibiting tumor growth $(p<0.05)$. The THDR-NPs treatment group showed the most significant inhibition on the growth of tumor cells $(p<$ 0.01), however, the rosiglitazone treatment group showed a weaker therapeutic effect $(p>0.05)$. The results correspond to in vitro cytotoxicity experiments (Figure 11A and B). After the end of the experiment, the collected tumors also corroborated this result (Figure 11C). The body weight changes of the treated mice were monitored during the experiment, as shown in Figure 11D, the body weight of the treated mice did not change significantly. The survival rate was also highest in the THDR-NPs treatment group within 50 days (Figure 11E).

The side effects of free DAS and ROZ drugs (mainly liver and kidney toxicity) will limit their therapeutic effects and increase the harm to patients. The nanoparticles we prepared are expected to reduce accumulation in liver and kidney organs and increase specific delivery to tumor cells, which can greatly reduce drug toxicity and improve efficacy. To verify this, we also performed HE analysis on organs removed from mice (Figure 12). HE analysis of liver and kidney shows that THDR-NPs can reduce the damage to liver and kidney. In the lung tissue, the lung tumors in the saline group were significantly infiltrated, the THDR-NPs group had the most obvious alveoli and decreased inflammatory cells, indicating that nanoparticles can better inhibit tumor metastasis. ${ }^{33}$ In addition, no abnormal changes in other major organs were observed in mice.

\section{Conclusion}

In summary, we have presented a simple strategy to assemble active targeting, $\mathrm{pH}$-sensitive drug release, and combinational drug delivery in a micelle. We designed to increase drug accumulation at the tumor site by HA-DAS polymer to target CD44 protein overexpressed on tumor surfaces and $\mathrm{pH}$-sensitive ester bonds. The EPR effect of nanoparticles is helpful to prolong the retention time of drugs in the nanosystem and achieve the effect of continuous release of drugs. The combination treatment of DAS and ROZ had stronger inhibitory effect on the proliferation and metastasis of breast cancer cells, reduced toxic and side effects. The study broadened the applications of micelles to multifunctional theranostic nanomedicine, 


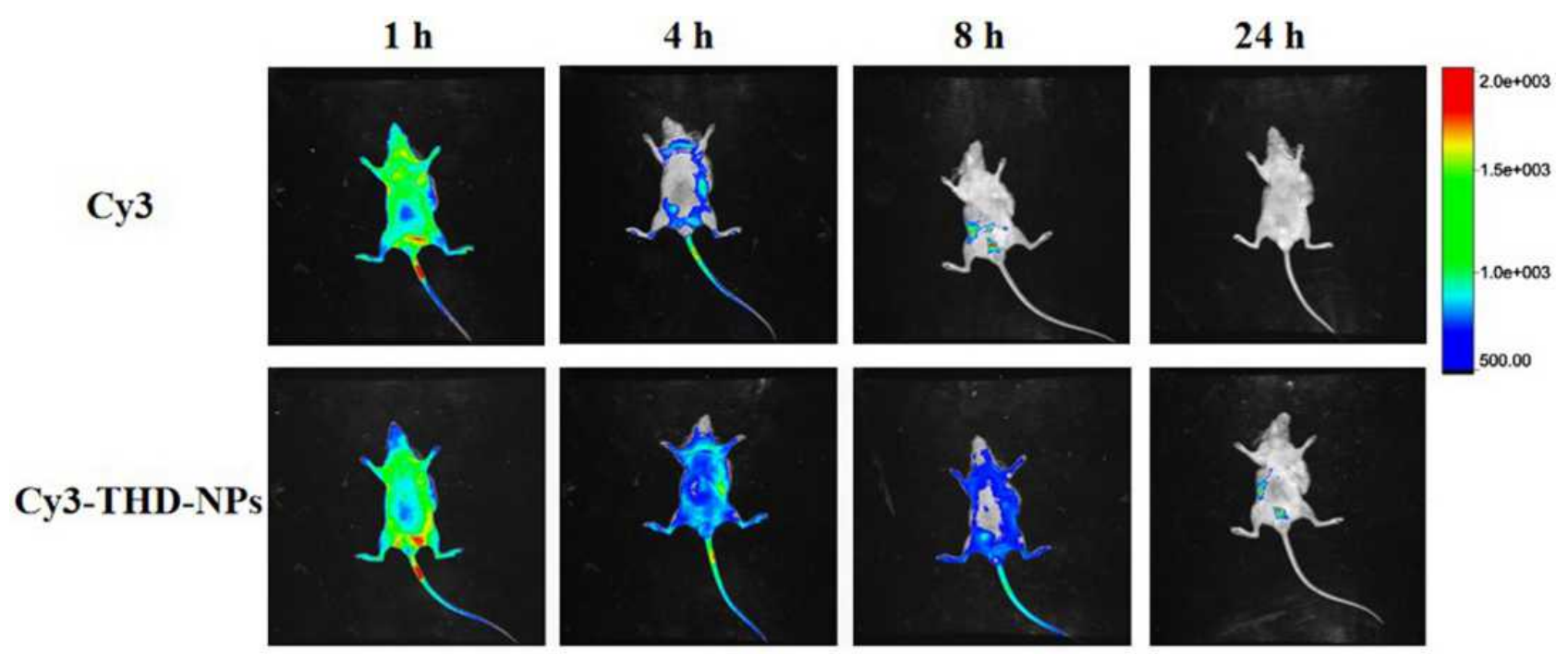

Figure $10 \mathrm{In}$ vivo fluorescence images of the MDA-MB-23I xenograft model after injection of Cy3 and Cy3-THD-NPs via the tail vein at I h, $4 \mathrm{~h}, 8 \mathrm{~h}$ and $24 \mathrm{~h}$. Abbreviation: Cy3-THD-NPs, HA-DAS and TPGS mixed micelle system loaded with Cy3.

A
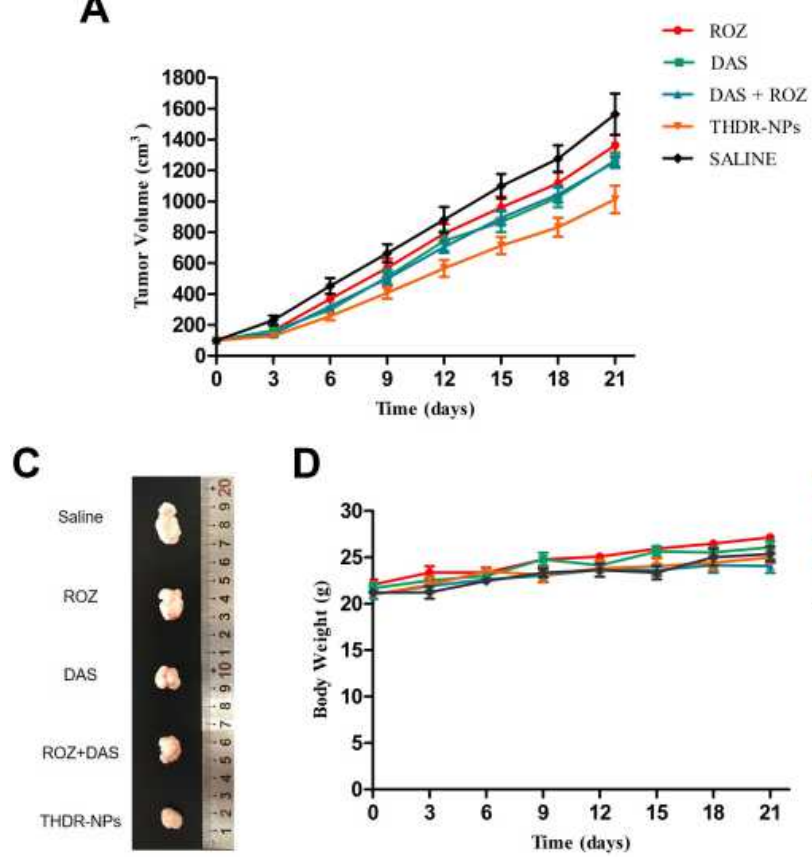

D

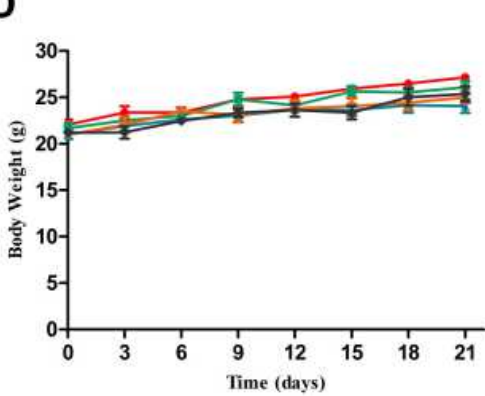

B

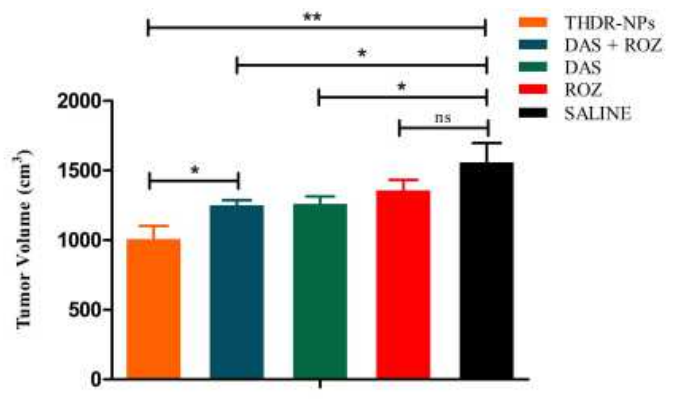

$\rightarrow \mathrm{ROZ}$

- DAS

- DAS + ROZ

* THDR-NPs

$\rightarrow$ SALINE
E

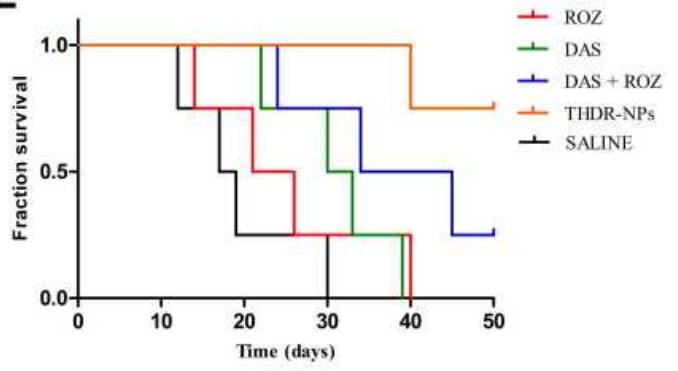

Figure II Tumor volume (A) and average body weight (D) of mice was used to evaluate the toxicity of the different treatments. (5 mg/kg DAS equivalent dose). Tumor volume (B) and the shape of representative tumor $(\mathbf{C})$ in each group and at the end point of the different treatments. (E) Survival curve of different treatment.

Notes: The tumor volume and average body weight are described as the mean $\pm S D(n=5)$. "ns" means non significant, $* p<0.05$, $* * p<0.01$.

Abbreviations: DAS, dasatinib; ROZ, rosiglitazone; THDR-NPs, HA-DAS and TPGS mixed micelle system loaded with ROZ. 


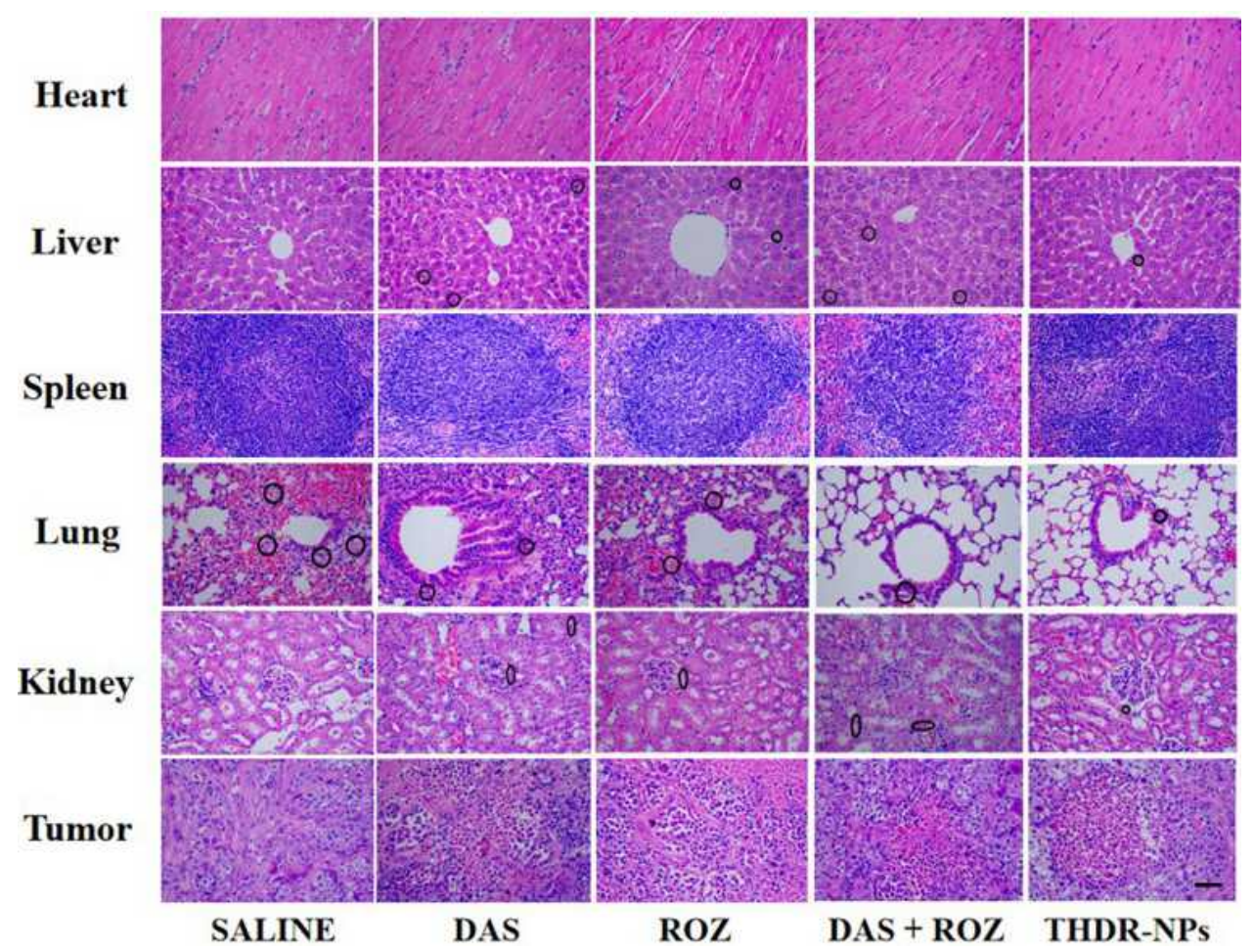

Figure 12 Representative HE staining of the heart, liver, spleen, lung, kidney and tumor from different treatment groups. Note: Scale bar $=50 \mu \mathrm{m}$.

which could be applied to a diverse range of hydrophobic drugs.

\section{Acknowledgments}

The authors would like to thank the Key Program of Anhui University Natural Science Research (Grants, KJ2018A0998) and Scientific Research Innovation Projects of Bengbu Medical College of Anhui Province (Grants, Byycx1929) for the financial support. The authors thank Ms. Xiaojiang Guo for her help on proofreading this manuscript.

\section{Disclosure}

The authors declare no conflicts of interest for this work.

\section{References}

1. Siegel RL, Miller KD, Jemal A. Cancer statistics, 2019. CA Cancer J Clin. 2019;69(1):7-34. doi:10.3322/caac.21551

2. DeSantis CE, Ma J, Gaudet MM, et al. Breast cancer statistics, 2019. CA Cancer J Clin. 2019;69(6):438-451. doi:10.3322/caac.21583

3. Ma R, Feng Y, Lin S, et al. Mechanisms involved in breast cancer liver metastasis. J Transl Med. 2015;13(1):64. doi:10.1186/s12967-0150425-0

4. Yeung KT, Yang J. Epithelial-mesenchymal transition in tumor metastasis. Mol Oncol. 2017;11(1):28-39. doi:10.1002/18780261.12017

5. Saitoh M. Involvement of partial EMT in cancer progression. J Biochem. 2018;164(4):257-264. doi:10.1093/jb/mvy047
6. Ishay-Ronen D, Diepenbruck M, Kalathur R, et al. Gain fat-lose metastasis: converting invasive breast cancer cells into adipocytes inhibits cancer metastasis. Cancer Cell. 2019;35(1):17-32. doi:10.1016/j.ccell.2018.12.002

7. Mace ML, Dahl J, Jabbour EJ. Which tyrosine-kinase inhibitor to use first in chronic phase chronic myelogenous leukemia? Expert Opin Pharmacother. 2015;16(7):999-1007. doi:10.1517/ 14656566.2015.1031107

8. Scher KS, Somlo G. Dasatinib: a novel therapy for breast cancer? Expert Opin Investig Drugs. 2013;22(6):795-801. doi:10.1517/ 13543784.2013.793308

9. Zeng F, Ju RJ, Liu L, et al. Efficacy in treating lung metastasis of invasive breast cancer with functional vincristine plus dasatinib liposomes. Pharmacology. 2018;101(1-2):43-53. doi:10.1159/000480737

10. Yao Q, Choi JH, Dai Z, et al. Improving tumor specificity and anticancer activity of dasatinib by dual-targeted polymeric micelles. ACS Appl Mater Interfaces. 2017;9(42):36642-36654. doi:10.1021/acsami.7b12233

11. Santos FP, Cortes J. Dasatinib for the treatment of Philadelphia chromosome-positive leukemias. Expert Opin Pharmacother. 2012;13(16):2381-2395. doi:10.1517/14656566.2012.725722

12. Ding F, Qiu J, Li Q, et al. Effects of rosiglitazone on proliferation and differentiation of duck preadipocytes. In Vitro Cell Dev Biol Anim. 2016;52(2):174-181. doi:10.1007/s11626-015-9958-z

13. Ishay-Ronen D, Christofori G. Targeting cancer cell metastasis by converting cancer cells into fat. Cancer Res. 2019;79(21):5471-5475. doi:10.1158/0008-5472.CAN-19-1242

14. Leveque D, Becker G, Bilger K, et al. Clinical pharmacokinetics and pharmacodynamics of dasatinib. Clin Pharmacokinet. 2020;59 (7):849-856. doi:10.1007/s40262-020-00872-4

15. Mizuta S, Sawa M, Tsurumi H, et al. Plasma concentrations of dasatinib have a clinical impact on the frequency of dasatinib dose reduction and interruption in chronic myeloid leukemia: an analysis of the DARIA 01 study. Int J Clin Oncol. 2018;23(5):980-988. doi:10.1007/s10147-018-1300-9 
16. Zhang C, Wang Y, Zhao Y, et al. Biodegradable micelles for NIR/ GSH-triggered chemophototherapy of cancer. Nanomaterials (Basel). 2019;9(1).

17. Qin L, Wu L, Jiang S, et al. Multifunctional micelle delivery system for overcoming multidrug resistance of doxorubicin. J Drug Target. 2018;26(4):289-295. doi:10.1080/1061186X.2017.1379525

18. Tockary TA, Foo W, Dirisala A, et al. Single-stranded DNA-packaged polyplex micelle as adeno-associated-virus-inspired compact vector to systemically target stroma-rich pancreatic cancer. ACS Nano. 2019;13(11):12732-12742. doi:10.1021/acsnano.9b04676

19. Panja S, Dey G, Bharti R, et al. Tailor-made temperature-sensitive micelle for targeted and on-demand release of anticancer drugs. ACS Appl Mater Interfaces. 2016;8(19):12063-12074. doi:10.1021/ acsami.6b03820

20. Williams K, Motiani K, Giridhar PV, et al. CD44 integrates signaling in normal stem cell, cancer stem cell and (pre)metastatic niches. Exp Biol Med (Maywood). 2013;238(3):324-338. doi:10.1177/ 1535370213480714

21. Termeer C, Sleeman JP, Simon JC. Hyaluronan-magic glue for the regulation of the immune response? Trends Immunol. 2003;24 (3):112-114. doi:10.1016/S1471-4906(03)00029-2

22. Karousou E, Misra S, Ghatak S, et al. Roles and targeting of the HAS/hyaluronan/CD44 molecular system in cancer. Matrix Biol. 2017;59:3-22. doi:10.1016/j.matbio.2016.10.001

23. Maudens P, Meyer S, Seemayer CA, et al. Self-assembled thermoresponsive nanostructures of hyaluronic acid conjugates for osteoarthritis therapy. Nanoscale. 2018;10(4):1845-1854. doi:10.1039/ C7NR07614B

24. Lin T, Yuan A, Zhao X, et al. Self-assembled tumor-targeting hyaluronic acid nanoparticles for photothermal ablation in orthotopic bladder cancer. Acta Biomater. 2017;53:427-438. doi:10.1016/j. actbio.2017.02.021

25. Son SU, Lim JW, Kang T, et al. Hyaluronan-based nanohydrogels as effective carriers for transdermal delivery of lipophilic agents: towards transdermal drug administration in neurological disorders. Nanomaterials (Basel). 2017;7(12):427. doi:10.3390/nano7120427
26. Li H, Yan L, Tang E, et al. Synthesis of TPGS/curcumin nanoparticles by thin-film hydration and evaluation of their anti-colon cancer efficacy in vitro and in vivo. Front Pharmacol. 2019;10:769. doi:10.3389/fphar.2019.00769

27. Zhang Z, Tan S, Feng SS. Vitamin E TPGS as a molecular biomaterial for drug delivery. Biomaterials. 2012;33(19):4889-4906. doi:10.1016/j.biomaterials.2012.03.046

28. Bhattacharya S, Ghosh A, Maiti S, et al. Delivery of thymoquinone through hyaluronic acid-decorated mixed pluronic(R) nanoparticles to attenuate angiogenesis and metastasis of triple-negative breast cancer. J Control Release. 2020;322:357-374. doi:10.1016/j. jconrel.2020.03.033

29. Du C, Qi Y, Zhang Y, et al. Epidermal growth factor receptor-targeting peptide nanoparticles simultaneously deliver gemcitabine and olaparib to treat pancreatic cancer with breast cancer 2 (BRCA2) mutation. ACS Nano. 2018;12(11):10785-10796. doi: $10.1021 /$ acsnano.8b01573

30. Zhu J, Huo Q, Xu M, et al. Bortezomib-catechol conjugated prodrug micelles: combining bone targeting and aryl boronate-based $\mathrm{pH}$-responsive drug release for cancer bone-metastasis therapy. Nanoscale. 2018;10(38):18387-18397. doi:10.1039/C8NR03899F

31. Bittel AM, Saldivar IS, Dolman NJ, et al. Superresolution microscopy with novel BODIPY-based fluorophores. PLoS One. 2018;13 (10):e206104. doi:10.1371/journal.pone.0206104

32. Tian Y, Li JC, Zhu JX, et al. Folic acid-targeted etoposide cubosomes for theranostic application of cancer cell imaging and therapy. Med Sci Monit. 2017;23:2426-2435. doi:10.12659/MSM.904683

33. Deng $\mathrm{Y}$, Song $\mathrm{P}$, Chen $\mathrm{X}$, et al. 3-Bromopyruvate-conjugated nanoplatform-induced pro-death autophagy for enhanced photodynamic therapy against hypoxic tumor. ACS Nano. 2020;14 (8):9711-9727. doi:10.1021/acsnano.0c01350
International Journal of Nanomedicine

\section{Publish your work in this journal}

The International Journal of Nanomedicine is an international, peerreviewed journal focusing on the application of nanotechnology in diagnostics, therapeutics, and drug delivery systems throughout the biomedical field. This journal is indexed on PubMed Central, MedLine, CAS, SciSearch ${ }^{\mathbb{}}$, Current Contents ${ }^{\mathbb{R}} /$ Clinical Medicine, $^{2}$

\section{Dovepress}

Journal Citation Reports/Science Edition, EMBase, Scopus and the Elsevier Bibliographic databases. The manuscript management system is completely online and includes a very quick and fair peer-review system, which is all easy to use. Visit http://www.dovepress.com/ testimonials.php to read real quotes from published authors. 